Sādhanā Vol. 27, Part 3, June 2002, pp. 353-363. () Printed in India

\title{
Hydraulics of free overfall in $\Delta$-shaped channels
}

\author{
SUBHASISH DEY and B RAVI KUMAR \\ Department of Civil Engineering, Indian Institute of Technology, Kharagpur \\ 721302, India \\ e-mail: sdey@ civil.iitkgp.ernet.in
}

MS received 15 October 2001; revised 13 February 2002

\begin{abstract}
In this paper, two methods are presented to analyse the free overfall in $\Delta$-shaped (equilateral triangle-shaped) channels. First, the flow upstream of a free overfall from smooth horizontal or mildly sloping $\Delta$-shaped channels is analysed theoretically to determine the end-depth-ratio (EDR), applying the momentum equation based on the Boussinesq approximation. Second, an alternate method for analysing free overfall in $\Delta$-shaped channels is also presented where the flow over a free overfall in a $\Delta$-shaped channel is simulated by that over a sharp-crested weir to calculate the EDR. The method of estimation of discharge from the known end depth is also presented for both the methods. These approaches eliminate the need of an experimentally determined pressure coefficient. Experiments are conducted to verify the results obtained from the present methods. Comparisons of the computed and experimental results are satisfactory.
\end{abstract}

Keywords. Brink depth; equilateral triangle shaped channels; end depth; free overfall; hydraulics; one-dimensional flow; open channel flow; steady flow.

\section{Introduction}

A free overfall is a situation in which the flow finds a sudden drop in the channel base, causing the flow to separate from the solid boundary to form a free nappe. A significant characteristic is that there is a strong departure from hydrostatic distribution of pressure caused by the strong accelerated downflow in the vicinity of the drop. In open channels, free overfall offers the possibility of being used as a measuring device of discharge. Pioneer experimental research was carried out by Rouse (1936) in mildly sloping rectangular channels to determine the enddepth-ratio (EDR = end depth / critical depth), which was found to be 0.715 . Since then a large number of investigations on free overfall have been carried out on various channels (Fathy \& Shaarawi 1954; Delleur et al 1956; Diskin 1961; Smith 1962; Rajaratnam \& Muralidhar 1964, 1968, 1970; Clarke 1965; Markland 1965; Anderson 1967; Strelkoff \& Moayeri 1970; Bauer \& Graf 1971; Ali \& Sykes 1972; Chow \& Han 1979; Hager 1983, 1999; Keller \& Fong 1989; Ferro 1992, 1999; Montes 1992; Marchi 1993; Gupta et al 1993; Murty Bhallamudi 1994; Anastasiadou-Partheniou \& Hatzigiannakis 1995; Clausnitzer \& Hager 1997; Davis et al 1998, 1999; Dey 1998 2000, 2001). 
Solutions of the potential flow theory to determine the hydraulic aspects of overfalls were given by Markland (1965), Clarke (1965), Strelkoff \& Moayeri (1970), Chow \& Han (1979), Matthew (1991) and Montes (1992). Jaeger (1948) solved the momentum and energy equations using the Boussinesq approximation to calculate the EDR in horizontal rectangular channels. Rajaratnam \& Muralidhar (1964b) presented experimental and analytical work on the overfall from circular channels. Anderson (1967) analysed the modified energy equation based on the Boussinesq approximation to determine the EDR for the rectangular overfall. The free vortex theory was applied by Ali \& Sykes (1972) for trapezoidal overfalls. Hager (1983) solved the momentum and extended energy equations to analyse the rectangular overfall considering the streamline inclination and curvature. An analytical approach, termed theory of a direct fluid sheet, was put forward by Naghdi \& Rubin (1981) to develop an exact solution of the non-linear equations. Marchi (1993) solved the two-dimensional overfall with the aid of the cnoidal wave theory. Empirical equations of EDR for trapezoidal overfalls were proposed by Gupta et al (1993). Also, the end depths in trapezoidal and exponential channels were analytically determined by Murty Bhallamudi (1994) using the momentum approach based on the Boussinesq approximation. AnastasiadouPartheniou \& Hatzigiannakis (1995) and Ferro (1999) simulated the free overfall by that over a sharp-crested weir. Analytical solutions for circular overfall given by Dey (1998b, 2001a) were based on the momentum equation and the simulation of a free overfall by that over a sharp-crested weir respectively. Dey (2001) also, studied the free overfall in elliptical channels. ISO 3874 (1977) and ISO 4371 (1984) recommended the flow estimation by the end depth method in rectangular and non-rectangular channels, respectively. The effect of bottom roughness on rectangular overfalls was experimentally studied by Delleur et al (1956), Rajaratnam et al (1976) and Kraijenhoff \& Dommerholt (1977), and its mathematical solution was given by Dey (1998a, 2000). However, no attempt has so far been made to analyse the free overfall in $\Delta$-shaped channels, which is a possible shape of a sewer.

In this paper, two separate methods are presented to analyse the free overfall in $\Delta$ shaped channels. First, an analytical model for a free overfall from smooth horizontally laid or mildly sloping $\Delta$-shaped channels is presented, applying a momentum approach based on the Boussinesq assumption. Second, an alternate approach for a free overfall in $\Delta$-shaped channels is also presented, where the flow over a fall in a $\Delta$-shaped channel is simulated by that over a sharp-crested weir to calculate the EDR and discharge. Both the methods eliminate the need for an experimentally determined pressure coefficient. The methods yield the EDR and discharge, which are verified by the experimental data. The above analyses are given for a flow regime approaching subcriticality. A flow regime approaching supercriticality being not so common in practice is beyond the realm of this study.

\section{Experimental set-up and procedure}

Experiments were conducted in two different horizontally laid $\Delta$-shaped channels (made of transparent perspex), having sides of $18 \mathrm{~cm}$ (channel 1) and $12 \mathrm{~cm}$ (channel 2). The lengths of the channels were $4 \mathrm{~m}$. Each channel was connected to an upstream supply. Water discharged through the downstream end of the channel into a measuring tank and finally drained into the reservoir. A valve in the upstream supply line controlled the discharge. The discharge was set by slowly opening the upstream valve until the desired height at the end section of the 
Table 1. Experimental data.

\begin{tabular}{|c|c|c|c|c|c|c|}
\hline Channel & $\begin{array}{c}b \\
(\mathrm{~cm})\end{array}$ & $\begin{array}{c}Q \\
\left(\mathrm{~cm}^{3} \mathrm{~s}^{-1}\right)\end{array}$ & $\hat{h}_{c}$ & $\hat{h}_{e}$ & $\tilde{h}_{e}$ & $\hat{Q}$ \\
\hline 1 & 18 & $\begin{array}{r}17824.41 \\
16007.64 \\
14595.46 \\
13639.59 \\
11373.10 \\
11374.87 \\
9261.11 \\
8253.22 \\
7306.86 \\
6546.58 \\
5935.18 \\
5673.51 \\
5036.94 \\
4239.29 \\
3385.21 \\
2917.41 \\
2484.03 \\
1850.22 \\
1249.03 \\
786.83\end{array}$ & $\begin{array}{l}0.6671 \\
0.6262 \\
0.5916 \\
0.5667 \\
0.5031 \\
0.5032 \\
0.4381 \\
0.4049 \\
0.3724 \\
0.3453 \\
0.3227 \\
0.3128 \\
0.2882 \\
0.2559 \\
0.2192 \\
0.1979 \\
0.1773 \\
0.1450 \\
0.1110 \\
0.0812\end{array}$ & $\begin{array}{l}0.4744 \\
0.4506 \\
0.4172 \\
0.3906 \\
0.3600 \\
0.3428 \\
0.3089 \\
0.2839 \\
0.2544 \\
0.2417 \\
0.2272 \\
0.2144 \\
0.1994 \\
0.1789 \\
0.1561 \\
0.1378 \\
0.1239 \\
0.1017 \\
0.0783 \\
0.0561\end{array}$ & $\begin{array}{l}0.7112 \\
0.7195 \\
0.7053 \\
0.6892 \\
0.7155 \\
0.6812 \\
0.7051 \\
0.7011 \\
0.6832 \\
0.6999 \\
0.7041 \\
0.6855 \\
0.6921 \\
0.6991 \\
0.7122 \\
0.6961 \\
0.6988 \\
0.7012 \\
0.7057 \\
0.6911\end{array}$ & $\begin{array}{l}0.5932 \\
0.5327 \\
0.4857 \\
0.4539 \\
0.3785 \\
0.3786 \\
0.3082 \\
0.2747 \\
0.2432 \\
0.2179 \\
0.1975 \\
0.1888 \\
0.1676 \\
0.1411 \\
0.1127 \\
0.0971 \\
0.0827 \\
0.0616 \\
0.0416 \\
0.0262\end{array}$ \\
\hline 2 & 12 & $\begin{array}{r}7738.46 \\
6778.14 \\
5905.46 \\
5288.86 \\
5266.99 \\
5014.46 \\
4612.18 \\
4126.17 \\
4138.76 \\
3459.38 \\
3394.18 \\
2915.30 \\
2638.02 \\
2357.93 \\
2141.94 \\
1803.38 \\
1564.69 \\
1252.70 \\
1029.22 \\
792.74\end{array}$ & $\begin{array}{l}0.7344 \\
0.6849 \\
0.6325 \\
0.5910 \\
0.5895 \\
0.5714 \\
0.5414 \\
0.5031 \\
0.5041 \\
0.4468 \\
0.4410 \\
0.3975 \\
0.3711 \\
0.3435 \\
0.3215 \\
0.2855 \\
0.2589 \\
0.2222 \\
0.1941 \\
0.1624\end{array}$ & $\begin{array}{l}0.5083 \\
0.4833 \\
0.4350 \\
0.4250 \\
0.4083 \\
0.3983 \\
0.3800 \\
0.3583 \\
0.3433 \\
0.3208 \\
0.3008 \\
0.2800 \\
0.2658 \\
0.2408 \\
0.2225 \\
0.2042 \\
0.1767 \\
0.1567 \\
0.1342 \\
0.1125\end{array}$ & $\begin{array}{l}0.6922 \\
0.7057 \\
0.6878 \\
0.7191 \\
0.6927 \\
0.6971 \\
0.7019 \\
0.7123 \\
0.6811 \\
0.7181 \\
0.6821 \\
0.7044 \\
0.7163 \\
0.7011 \\
0.6921 \\
0.7151 \\
0.6824 \\
0.7052 \\
0.6911 \\
0.6928\end{array}$ & $\begin{array}{l}0.7097 \\
0.6216 \\
0.5416 \\
0.4850 \\
0.4830 \\
0.4599 \\
0.4230 \\
0.3784 \\
0.3796 \\
0.3173 \\
0.3113 \\
0.2674 \\
0.2419 \\
0.2163 \\
0.1964 \\
0.1654 \\
0.1435 \\
0.1149 \\
0.0944 \\
0.0727\end{array}$ \\
\hline
\end{tabular}

channel resulted. Once it was reached, the corresponding discharge was recorded with the aid of a measuring tank. The end depths were measured carefully by a point gauge. Table 1 presents the experimental data.

\section{First model of the EDR}

This model is based on the assumption of pseudo-uniform flow, where frictional resistance being very small is balanced by the streamwise gravity component of force (Dey 1998). Apply- 


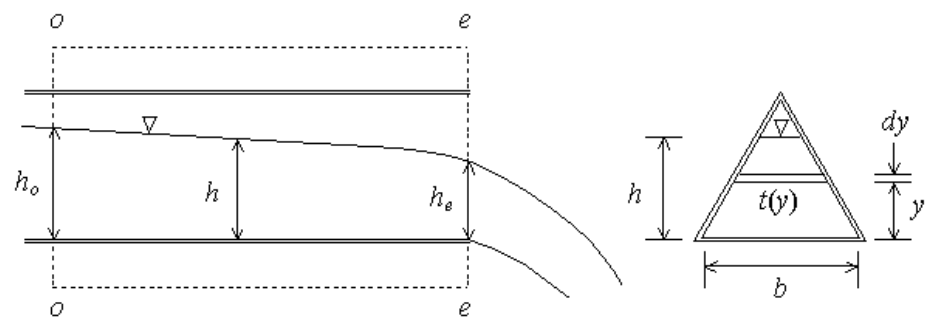

(a)

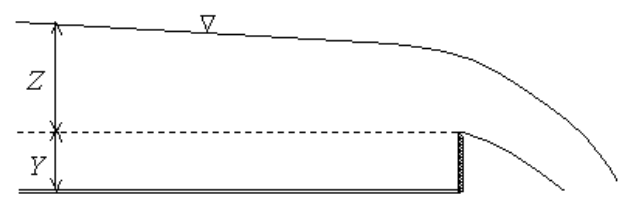

(b)

Figure 1. Definition sketch of (a) a free overfall in a $\Delta$-shaped channel and (b) a weir flow.

ing the one-dimensional momentum equation between sections $x=-L$ (far upstream of the end section) and $x=-x$ for the flow situation under consideration (figure 1a), one obtains

$$
f_{o}-f=\rho Q\left(\beta V-\beta_{o} V_{o}\right),
$$

where $f=$ total pressure force, $\rho=$ mass density of fluid, $Q=$ discharge, $\beta=$ Boussinesq coefficient, and $V=$ mean flow velocity. Subscript ' $o$ ' refers to section $x=-L$. For simplicity, in this analysis, $b$ is assumed to be unity. For a curvilinear flow with constant acceleration $a_{y}$ normal to the direction of flow, the intensity of pressure $p$ at $y$ above the bottom is obtained from the integration of the Euler equation as

$$
-\frac{\partial}{\partial y}(p+\rho g y)=\rho a_{y},
$$

where $g=$ gravitational constant. According to the Boussinesq theory (Jaeger 1957), as the free surface curvature of a free overfall is relatively small and varies from a finite value at the surface to zero at the channel boundary, a linear variation of the streamline curvature with depth is assumed. Hence, the radius of curvature $r$ of a streamline at $y$ is written as

$$
1 / r \approx(y / h)\left(1 / r_{s}\right)
$$

where $h=$ flow depth, and $r_{s}=$ radius of curvature of the free surface. As the free surface curvature is small, it can be approximated as

$$
1 / r_{s} \approx \mathrm{d}^{2} h / \mathrm{d} x^{2}
$$

If the flow velocity at any depth equals the mean flow velocity $V$ (which is a function of $x$ ), the vertical acceleration $a_{y}\left(=V^{2} / r\right)$ based on the above assumption is given by

$$
a_{y}=k y,
$$


where

$$
k=\left(V^{2} / h\right)\left(\mathrm{d}^{2} h / \mathrm{d} x^{2}\right) .
$$

The above assumption for the estimation of $r_{s}$ was found to be adequate in many flow situations involving a small streamline curvature (Jaeger 1957). Using (5), (2) is integrated within $y$ to $h$ to obtain the expression for the pressure distribution as

$$
p=\rho g(h-y)+o .5 \rho k\left(h^{2}-y^{2}\right) .
$$

The pressure force $f$ at section $x=-x$ is derived from

$$
f=\int_{0}^{h} p t(y) d y,
$$

where $t(y)=$ width of the channel at $y$. It is expressed for a $\Delta$-shaped channel of side $b$ as

$$
t(y)=b-(2 / \sqrt{3}) y .
$$

Thus, using (7) and (9) in (8), $f$ is expressed as

$$
f=\rho g z^{3} \frac{\hat{h}^{3}}{\sqrt{3}}\left[1-\frac{\hat{h}}{3}\right]+\rho k z^{4} \frac{\hat{h}^{3}}{2 \sqrt{3}}\left[\frac{4}{3}-\frac{\hat{h}}{2}\right],
$$

where $\hat{h}=h / z$, and $z=$ height of the channel, which is given by

$$
z=(\sqrt{3} / 2) b \text {. }
$$

At the far upstream section $(x=-L), k=0$ and $\hat{h}$ is replaced by $\hat{h}_{o}$. Thus, the hydrostatic pressure force $f_{o}$ obtained from (10) is

$$
f_{o}=\rho g z^{3}\left(\hat{h}^{3} / \sqrt{3}\right)\left[1-\left(\hat{h}_{o} / 3\right)\right]
$$

where $\hat{h}_{o}=h_{o} / z$. The continuity equation between sections $x=-L$ and $x=-x$ is

$$
Q=V_{o} A_{o}=V A,
$$

where $Q=$ discharge, and $A=$ flow area. The flow area is expressed for a $\Delta$-shaped channel as

$$
A=\left(z^{2} / \sqrt{3}\right)(2-\hat{h}) \hat{h} .
$$

Using (10)-(14) and incorporating $F_{o}$ into (1) with $\beta=\beta_{o}=1$, yields

$$
\begin{aligned}
\hat{h}_{o}^{2}\left[1-\frac{\hat{h}_{o}}{3}\right]-\hat{h}^{2}\left[1-\frac{\hat{h}}{3}\right]-\frac{k z \hat{h}^{3}}{2 g}\left[\frac{4}{3}-\frac{\hat{h}}{2}\right] \\
=\frac{\mathrm{F}_{o}^{2}}{2} \cdot \frac{\left(2-\hat{h}_{o}\right)^{3} \hat{h}_{o}^{3}}{1-\hat{h}_{o}}\left[\frac{1}{(2-\hat{h}) \hat{h}}-\frac{1}{\left(2-\hat{h}_{o}\right) \hat{h}_{o}}\right],
\end{aligned}
$$


where

$$
\begin{aligned}
\mathrm{F}_{o} & =\sqrt{6} \hat{Q}\left\{\left(1-\hat{h}_{o}\right)^{1 / 2} /\left[\left(2-\hat{h}_{o}\right) \hat{h}_{o}\right]^{1.5}\right\} \\
\hat{Q} & =Q /\left(g^{0.5} z^{2.5}\right) .
\end{aligned}
$$

The EDR, which is the ratio of end depth $\left(h_{e}\right)$ to critical depth $\left(h_{c}\right)$, is computed for a $\Delta$-shaped channel using the preceding equations. According to Anderson (1967), the free surface profile is a continuous falling surface upstream and downstream of the end section. To be more explicit, the free surface of the flow passes through the brink and ends up as a parabolic trajectory of a gravity fall. Hence, the rate of change of slope of the free surface at the end section $(x=0)$, as was assumed by Anderson (1967), is

$$
\left(\mathrm{d}^{2} h / \mathrm{d} x^{2}\right)_{x=0}=-g / V_{e}^{2}
$$

where subscript $e$ refers to the end section $(x=0)$. Using $(17), k_{e}$ at the end section determined from (6) is

$$
k_{e}=-g / h_{e}
$$

Applying (15) to the end section $\left(\hat{h}=\hat{h}_{e}\right)$ and substituting $k_{e}$ from (18) in (15), a generalized equation for the EDR is derived as

$$
\begin{aligned}
\hat{h}_{o}^{2}\left[1-\frac{\hat{h}_{o}}{3}\right]-\hat{h}_{e}^{2}\left[1-\frac{\hat{h}_{e}}{3}\right]+\frac{\hat{h}_{e}^{2}}{2}\left[\frac{4}{3}-\frac{\hat{h}_{e}}{2}\right] \\
=\frac{\mathrm{F}_{o}^{2}}{2} \cdot \frac{\left(2-\hat{h}_{o}\right)^{3} \hat{h}_{o}^{3}}{1-\hat{h}_{o}}\left[\frac{1}{\left(2-\hat{h}_{e}\right) \hat{h}_{e}}-\frac{1}{\left(2-\hat{h}_{o}\right) \hat{h}_{o}}\right] .
\end{aligned}
$$

When the stream-wise slope of the channel is either horizontal or mild, the flow becomes critical $\left(h_{o}=h_{e}\right)$ upstream of the control section. Thus, the upstream Froude number $\mathrm{F}_{o}$ is unity. Introducing $\mathrm{F}_{o}=1$ and $\hat{h}_{o}=\hat{h}_{c}$ in (19), we get

$$
\begin{aligned}
\hat{h}_{c}^{2}\left[1-\frac{\hat{h}_{c}}{3}\right]-\hat{h}_{e}^{2}\left[1-\frac{\hat{h}_{e}}{3}\right]+\frac{\hat{h}_{e}^{2}}{2}\left[\frac{4}{3}-\frac{\hat{h}_{e}}{2}\right] \\
=\frac{1}{2} \cdot \frac{\left(2-\hat{h}_{c}\right)^{3} \hat{h}_{c}^{3}}{1-\hat{h}_{c}}\left[\frac{1}{\left(2-\hat{h}_{e}\right) \hat{h}_{e}}-\frac{1}{\left(2-\hat{h}_{c}\right) \hat{h}_{c}}\right] .
\end{aligned}
$$

where $c$ refers to a critical state of flow. Equation (20) is an implicit equation. Therefore, it is solved numerically, and the EDR $\tilde{h}_{e}$ is calculated from the following non-dimensional equation:

$$
\tilde{h}_{e}=h_{e} / h_{c}=\hat{h}_{e} / \hat{h}_{c}
$$

\section{Second model of the EDR (alternate approach)}

The flow over a free overfall in a $\Delta$-shaped channel (figure 1b) can be assumed to be similar to the flow over a sharp-crested weir having same section with a crest $Y=0$ and head above the 
crest $Z=h_{o}$ (Rouse 1936; Anastasiadou-Partheniou \& Hatzigiannakis 1995; Ferro 1999). As is done to compute the discharge over a sharp-crested weir, a zero pressure distribution and parallel streamlines at the end section are assumed, neglecting the compaction of the nappe. The flow velocity at the end section is calculated by applying the Bernoulli equation on a streamline between the far upstream section at $x=-L$, where the pressure is hydrostatic, and the end section at $x=0$. The discharge $Q$ is computed using the following equation:

$$
Q=C_{d} \sqrt{2 g} \int_{0}^{h_{o}} t(H-y)^{1 / 2} \mathrm{~d} y,
$$

where $C_{d}=$ coefficient of discharge $\left(=C_{v} C_{c}\right), C_{v}=$ coefficient of velocity, $C_{c}=$ coefficient of contraction $\left(=A_{e} / A_{o}\right)$, and $H=$ total head. $H$ at the far upstream section $(x=-L)$ is given by

$$
H=h_{o}+\left(V_{o}^{2} / 2 g\right) \text {. }
$$

Using (9) in(22), $Q$ is expressed as

$$
Q=2 \sqrt{2 / 3} C_{v} C_{c} z^{2.5} \sqrt{g} \int_{0}^{\hat{h}_{o}}(1-\hat{y})(\hat{H}-\hat{y})^{1 / 2} \mathrm{~d} \hat{y},
$$

where $\hat{y}=y / z$, and $\hat{H}=H / z$. The coefficient of contraction $C_{c}$ can be expressed as

$$
C_{c}=\left(2-\hat{h}_{e}\right) \hat{h}_{e} /\left[\left(2-\hat{h}_{o}\right) \hat{h}_{o}\right] .
$$

Using (25) in (24) and normalizing, yields

$$
\hat{Q}=2 \sqrt{2 / 3} C_{v} \frac{\left(2-\hat{h}_{e}\right) \hat{h}_{e}}{\left(2-\hat{h}_{o}\right) \hat{h}_{o}} \int_{0}^{\hat{h}_{o}}(1-\hat{y})(\hat{H}-\hat{y})^{1 / 2} \mathrm{~d} \hat{y} .
$$

Integrating (26) and using (16a), we can write

$$
\begin{array}{r}
\mathrm{F}_{o} \frac{3\left[\hat{h}_{o}\left(2-\hat{h}_{o}\right)\right]^{2.5}}{8 C_{v}\left(1-\hat{h}_{o}\right)^{0.5}}=\left(2-\hat{h}_{e}\right) \hat{h}_{e}\left\{\left(\hat{H}-\hat{h}_{o}\right)^{3 / 2}\left[\frac{1}{5}\left(2 \hat{H}+3 \hat{h}_{o}\right)-1\right]\right. \\
\left.-\hat{H}^{3 / 2}\left(\frac{2}{5} \hat{H}-1\right)\right\} .
\end{array}
$$

Introducing Froude number in (23), $\hat{H}$ can be given by

$$
\hat{H}=\hat{h}_{o}+\frac{\mathrm{F}_{o}^{2}}{4} \cdot \frac{\left(2-\hat{h}_{o}\right) \hat{h}_{o}}{1-\hat{h}_{o}} .
$$

Introducing $\mathrm{F}_{o}=1$ and $\hat{h}_{o}=\hat{h}_{c}$ in (27) and (28), one gets

$$
\begin{aligned}
\frac{3\left[\hat{h}_{c}\left(2-\hat{h}_{c}\right)\right]^{2.5}}{8 C_{v}\left(1-\hat{h}_{c}\right)^{0.5}}=\left(2-\hat{h}_{e}\right) \hat{h}_{e}\left\{( \hat { H } - \hat { h } _ { c } ) ^ { 3 / 2 } \left[\frac{1}{5}\left(2 \hat{H}+3 \hat{h}_{c}-1\right]\right.\right. & \left.-\hat{H}^{3 / 2}\left(\frac{2}{5} \hat{H}-1\right)\right\}, \\
\hat{H} & =\hat{h}_{c}+\frac{1}{4} \cdot \frac{\left(2-\hat{h}_{c}\right) \hat{h}_{c}}{1-\hat{h}_{c}}
\end{aligned}
$$


Equation (29) can be expressed as a quadratic equation. It is

$$
\hat{h}_{e}^{2}-2 \hat{h}_{e}+\lambda=0
$$

where $\lambda=\xi_{1} / \xi_{2}$, and

$$
\begin{aligned}
& \xi_{1}=\frac{3\left[\hat{h}_{c}\left(2-\hat{h}_{c}\right)\right]^{2.5}}{8 C_{v}\left(1-\hat{h}_{c}\right)^{0.5}} \\
& \xi_{2}=\left(\hat{H}-\hat{h}_{c}\right)^{3 / 2}\left[\frac{1}{5}\left(2 \hat{H}+3 \hat{h}_{c}\right)-1\right]-\hat{H}^{3 / 2}\left(\frac{2}{3} \hat{H}-1\right)
\end{aligned}
$$

The feasible solution of (31) is

$$
\hat{h}_{e}=1-(1-\lambda)^{1 / 2} \text {. }
$$

For a given $\hat{h}_{c}, \hat{H}$ is computed from (30). Then, $\hat{h}_{e}$ is solved from (33), and finally, EDR $\tilde{h}_{e}$ is estimated from (21). As value of $C_{v}$ for flow over free overfalls is not available as yet, (33) is required to be calibrated extensively. The experimental data were used to calibrate (33), making $C_{v}$ a free parameter. For this purpose, the experimental data of $\hat{h}_{c}$ and $\hat{h}_{e}$ were used as source data. As the variation of estimated $C_{v}$ is small, the mean value of $C_{v}$ obtained as 0.998 was used here.

\section{The discharge}

The concept of free overfall from $\Delta$-shaped channels is utilized to estimate the discharge using a known end depth. The equation of discharge obtained from continuity equation is

$$
Q=A_{o} V_{o}
$$

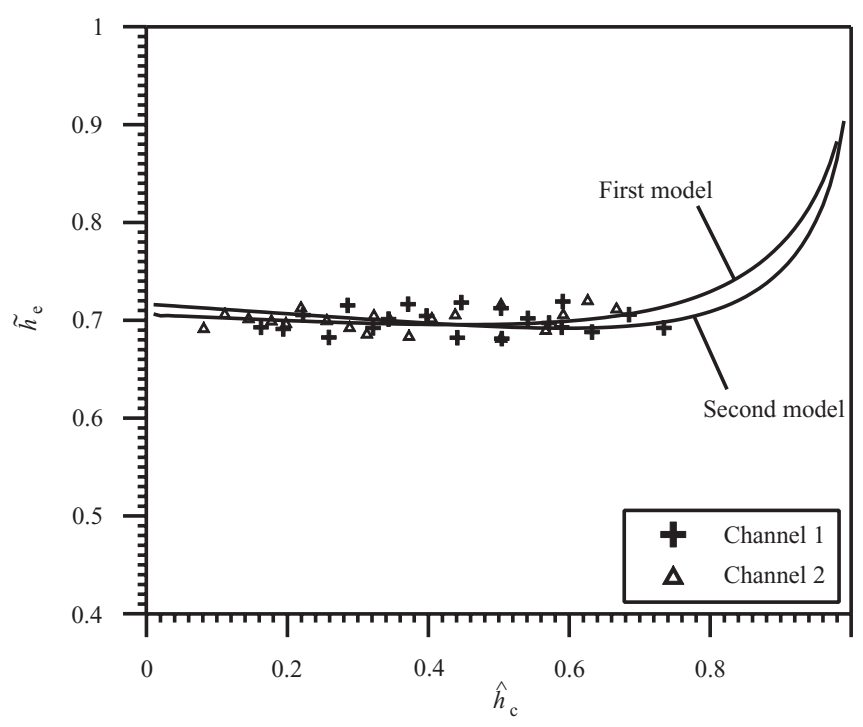

Figure 2. EDR $\tilde{h}_{e}$ as a function of $\hat{h}_{c}$. 


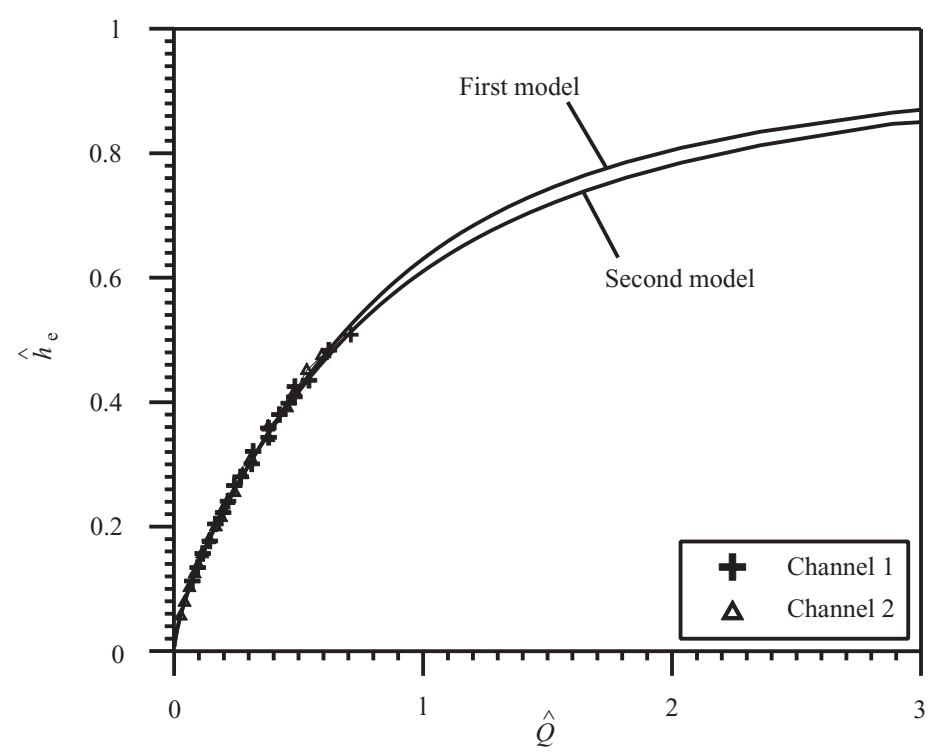

Figure 3. Variation of $\hat{h}_{e}$ with $\hat{Q}$.

Introducing $\mathrm{F}_{o}=1$ and $\hat{h}_{o}=\hat{h}_{c}$ in (34), one gets

$$
\hat{Q}=\frac{1}{\sqrt{6}} \cdot \frac{\left[\left(2-\hat{h}_{c}\right) \hat{h}_{c}\right]^{1.5}}{\left(1-\hat{h}_{c}\right)^{0.5}} .
$$

The results of both EDR models can be used to evaluate non-dimensional discharge $\hat{Q}$ from (35).

\section{Results}

The dependence of $\tilde{h}_{e}$ on $\tilde{c}$ is shown in figure 2. The curve obtained from the first model lies almost at the mid zone of the experimental data in the range of $0.111 \leq \hat{h}_{c} \leq .0 .734$. For the present case, the EDR $\tilde{h}_{e}$ has a value of around 0.695 up to $\hat{h}_{c}=0.70$. The curve rises sharply from $\hat{h}_{c}=0.80$. The curve obtained from this model corresponds closely to the experimental data with an accuracy of $\pm 5 \%$. Using $C_{v}=0.998$, the dependency of $\tilde{h}_{e}$ on $\tilde{h}_{c}$ obtained from the second model is also shown in figure 2 . The EDR $\tilde{h}_{e}$ varies almost linearly from 0.715 to 0.685 up to $\hat{h}_{c}=0.70$. The curve obtained from the second model has an agreement with the experimental data and the first model. Non-dimensional discharge $\hat{Q}$ is calculated using (35) for both the models. The variations of $\hat{h}_{e}$ with $\hat{Q}$ for both the models are presented in figure 3 . The experimental observations are agreeable with the curves obtained from the present models with an accuracy of $\pm 5 \%$. Figure 3 can be used to estimate the discharge from measured end-depth.

\section{Conclusions}

First, the free overfall in horizontal or mildly sloping $\Delta$-shaped channels has been analysed applying the momentum equation based on the Boussinesq approximation. In sub-critical 
approaching flows, the EDR has been related to the critical depth and has been found to be around 0.695 . The mathematical solutions have allowed estimation of discharge from the known end depth. Second, a simplified approach for computation of the end depth for a free overfall in $\Delta$-shaped channels has been presented. The flow over a fall in a $\Delta$-shaped channel has been simulated by that over a sharp-crested weir to calculate the end-depth ratio. The enddepth ratio is varying almost linearly from 0.715 to 0.685 for a critical depth-channel height ratio up to 0.70 . The method of estimation of discharge from the known end depth has also been presented. Both the models have corresponded satisfactorily to the experimental data.

The writers are grateful to the Late Bimalundu Dey for his helpful suggestions during the preparation of the paper.

\section{References}

Ali K H M, Sykes A 1972 Free-vortex theory applied to free overfall. J. Hydraul. Div., Am. Soc. Civ. Eng. 98: 973-979

Anastasiadou-Partheniou L, Hatzigiannakis E 1995 General end-depth-discharge relationship at free overfall in trapezoidal channel. J. Irrig. Drain. Eng., Am. Soc. Civ. Eng. 121: 143-151

Anderson M V 1967 Non-uniform flow in front of a free overfall. Acta Polytech. Scand. 42: 1-24

Bauer S W, Graf W H 1971 Free overfall as flow measuring device. J. Irrig. Drain. Div., Am. Soc. Civ. Eng. 97: 73-83

Chow W L, Han T 1979 Inviscid solution for the problem of the free overfall. J. Appl. Mech. 46: 1-5

Clausnitzer B, Hager W H 1997 Outflow characteristics from circular pipe. J. Hydraul. Eng., Am. Soc. Civ. Eng. 123: 914-917

Clarke N S 1965 On two-dimensional inviscid flow in a waterfall. J. Fluid Mech. 22: 359-369

Davis A C, Ellett B G S, Jacob R P 1998 Flow measurement in sloping channels with rectangular free overfall. J. Hydraul. Eng., Am. Soc. Civ. Eng. 124: 760-763

Davis A C, Jacob R P, Ellett B G S 1999 Estimating trajectory of free overfall nappe. J. Hydraul. Eng., Am. Soc. Civ. Eng. 125: 79-82

Delleur J W, Dooge J C I, Gent K W 1956 Influence of slope and roughness on the free overfall. J. Hydraul. Div., Am. Soc. Civ. Eng. 82: 30-35

Dey S 1998a Free overfall in rough rectangular channels: a computational approach. Water, Maritime and Energy, Proc. Inst. Civ. Eng. (London) 130: 51-54

Dey S 1998b End depth in circular channels. J. Hydraul. Eng., Am. Soc. Civ. Eng. 124: 856-863

Dey S 2000 End depth in steeply sloping rough rectangular channels. Sādhanā 25: 1-10

Dey S 2001a The EDR in circular channels. J. Irrig. Drain. Eng., Am. Soc. Civ. Eng. 127: 110-112

Dey S 2001b Flow metering by end-depth method in elliptic channels. Dam Eng. 12: 5-19

Dey S 2001c Flow measurement by the end-depth method in inverted semicircular channels. Flow Measure Instrum. 12: 253-258.

Diskin M H 1961 The end depth at a drop in trapezoidal channels. J. Hydraul. Div., Am. Soc. Civ. Eng. 87: 11-32

Fathy A, Shaarawi M A 1954 Hydraulics of free overfall. Proc. ASCE 80, Reston, pp. 1-12

Ferro V 1992 Flow measurement with rectangular free overfall. J. Irrig. Drain. Eng., Am. Soc. Civ. Eng. 118: 956-970

Ferro V 1999 Theoretical end-depth-discharge relationship for free overfall. J. Irrig. Drain. Eng., Am. Soc. Civ. Eng. 125: 40-44

Gupta R D, Jamil M, Mohsin M 1993 Discharge prediction in smooth trapezoidal free overfall (positive, zero and negative slopes). J. Irrig. Drain. Eng., Am. Soc. Civ. Eng. 119: 215-224 
Hager W H 1983 Hydraulics of the plane overfall. J. Hydraul. Eng., Am. Soc. Civ. Eng. 109: 1683-1697 Hager W H 1999 Cavity outflow from a nearly horizontal pipe. Int. J. Multiphase flow 25: 349-364

ISO 38741977 End depth method for estimation of flow in rectangular channels with a free overfall. International Organization for Standardization, Geneva

ISO 43711984 End depth method for estimation of flow in non-rectangular channels with a free overfall. International Organization for Standardization, Geneva

Jaeger C 1948 Hauteur d'eau a l'extremite d'un long deversoir. La Houille Blanche 3: 518-523

Jaeger C 1957 Engineering fluid mechanics (New York: St. Martin's Press)

Keller R J, Fong S S 1989 Flow measurements with trapezoidal free overfall. J. Irrig. Drain. Eng., Am. Soc. Civ. Eng. 115: 125-136

Kraijenhoff D A, Dommerholt A 1977 Brink depth method in rectangular channel. J. Irrig. Drain. Div., Am. Soc. Civ. Eng. 103: 171-177

Marchi E 1993 On the free overfall. J. Hydraul. Res. 31: 777-790

Markland E 1965 Calculation of flow at a free overfall by relaxation method. Proc. Inst. Civ. Eng. (London) 31: 71-78

Matthew G H 1991 Higher order, one dimensional equation of potential flow in open channels. Proc. Inst. Civ. Eng. (London) 90: 187-210

Montes J S 1992 A potential flow solution for the free overfall. Water, Maritime and Energy, Proc. Inst. Civ. Eng. (London) 96: 259-266

Murty Bhallamudi S 1994 End depth in trapezoidal and exponential channels. J. Hydraul. Res. 32: 219-232

Naghdi P M, Rubin M B 1981 On inviscid flow in a waterfall. J. Fluid Mech. 103: 375-387

Rajaratnam N, Muralidhar D 1964a End depth for exponential channels. J. Irrig. Drain. Div., Am. Soc. Civ. Eng. 90: 17-36

Rajaratnam N, Muralidhar D 1964b End depth for circular channels. J. Hydraul. Div., Am. Soc. Civ. Eng. 90: 99-119

Rajaratnam N, Muralidhar D 1968a Characteristics of rectangular free overfall. J. Hydraul. Res. 6: 233-258

Rajaratnam N, Muralidhar D 1968b The rectangular free overfall. J. Hydraul. Div., Am. Soc. Civ. Eng. 94: 849-850

Rajaratnam N, Muralidhar D 1970 The trapezoidal free overfall. J. Hydraul. Res. 8: 419-447

Rajaratnam N, Muralidhar D, Beltaos S 1976 Roughness effects on rectangular overfall. J. Hydraul. Div., Am. Soc. Civ. Eng. 102: 599-614

Rouse H 1936 Discharge characteristics of the free overfall. Civ. Eng. 6: 257-260

Smith C D 1962 Brink depth for a circular channel. J. Hydraul. Div., Am. Soc. Civ. Eng. 88: 125-134

Strelkoff T, Moayeri M S 1970 Pattern of potential flow in a free overfall. J. Hydraul. Div., Am. Soc. Civ. Eng. 96: 879-901 